\title{
Probable right ventricular dysplasia and patent foramen ovale presenting with cyanosis and clubbing in a patient with characteristics of Noonan syndrome
}

\author{
Peter Wilmshurst, Philip Da Costa
}

\begin{abstract}
Probable right ventricular dysplasia and a patent foramen ovale resulted in cyanotic heart disease in a patient with some characteristics of Noonan syndrome.
\end{abstract}

(Br Heart f 1995;74:471-475)

Keywords: cyanotic heart disease; right ventricular dysplasia; patent foramen ovale, Noonan syndrome

Gerlis et al suggested that there are two clinically and morphologically distinct forms of right ventricular myodystrophies. ${ }^{1}$ Uhl's anomaly is characterised by the absence of right ventricular myocardium, so that the endocardial and epicardial layers remain in contact. This results in congestive heart failure in neonatal or infant life. In arrhythmogenic right ventricular dysplasia (cardiomyopathy) there is patchy replacement of the parietal wall of the right ventricle by fibrofatty tissue, and patients typically present with ventricular tachyarrhythmias or sudden death, usually in early adult life. One patient with arrhythmogenic right ventricular dysplasia with haemodynamic features of right ventricular restriction and abnormal myocyte mitochondrial ultrastructure has been described. $^{2}$

We report a previously undescribed presentation of right ventricular dysplasia, namely clubbing, polycythaemia, and arterial hypoxaemia. Right-to-left shunting across a coincident patent foramen ovale was facilitated by relatively high right heart filling pressures because the patient had pure right ventricular restriction with normal left ventricular function. There was no clinical or electrocardiographic evidence of arrhythmias.

The Royal Infirmary, Huddersfield P Wilmshurst

Seacroft and Killingbeck Hospitals, Leeds
$P$ Da Costa

Correspondence to: Dr P Wilmshurst, Huddersfield, HD3 3EA. Accepted for publication 21 November 1994
The patient had some characteristics of Noonan syndrome.

\section{Case report}

A white girl was referred for paediatric assessment at the age of 10 because of a long history of fatigue, dyspnoea on exertion, and blue lips. She was small for her age (below the third centile for height and between the third and tenth centiles for weight). She had central cyanosis and cold extremities. No other abnormality was detected on cardiovascular or respiratory examination. The chest $x$ ray was normal. Haemoglobin concentration was $17 \cdot 4 \mathrm{~g} / \mathrm{dl}$. Skin lesions resembling spider angiomata were noted. Because of the rash, liver function tests were performed and urinary excretion of 5-hydroxy-indole acetic acid were measured and were normal. No other investigations were performed at that time.

During the next 15 years she had hospital treatment for minor trauma and minor surgery. On those occasions her haemoglobin concentration was consistently raised $(16.9-20.5 \mathrm{~g} / \mathrm{dl})$ but no investigations or treatment of polycythaemia were given. When she was 26 years old she was referred for the opinions of an haematologist and a physician because of polycythaemia. She stated that for many years she had been "purple" and that she was breathless on exertion and had cold extremities. She described intermittent claudication and a cough productive of green sputum. She had smoked 10 cigarettes daily since the age of 16 and had intermittently taken an oral contraceptive pill. She had central cyanosis and clubbing of digits. Blood pressure in the arms was $100 / 80 \mathrm{~mm} \mathrm{Hg}$. There was no other abnormality on examination.

The haemoglobin concentration in whole blood was $20.4 \mathrm{~g} / \mathrm{dl}$ with a haematocrit of $0 \cdot 58$. White cell count, platelet count, and chest $x$ ray were normal. The electrocardiogram showed sinus rhythm with normal $\mathrm{P}$ wave configuration, QRS axis $+105^{\circ}$, and $T$ wave inversion in leads V1-V4 (fig 1). The echocardiogram showed a dilated right ventricle but no other abnormality. A perfusion lung scan was normal. No other investigations were performed.

Primary pulmonary hypertension was diagnosed even though many features were atypical and she had periodic venesection to maintain her haemoglobin concentration at about $16 \mathrm{~g} / \mathrm{dl}$. Subsequently her exercise tolerance declined slowly because of increased dyspnoea and fatigue, despite treatment with diuretics. Angina and ankle oedema also developed. 
Figure 1 Electrocardiogram.

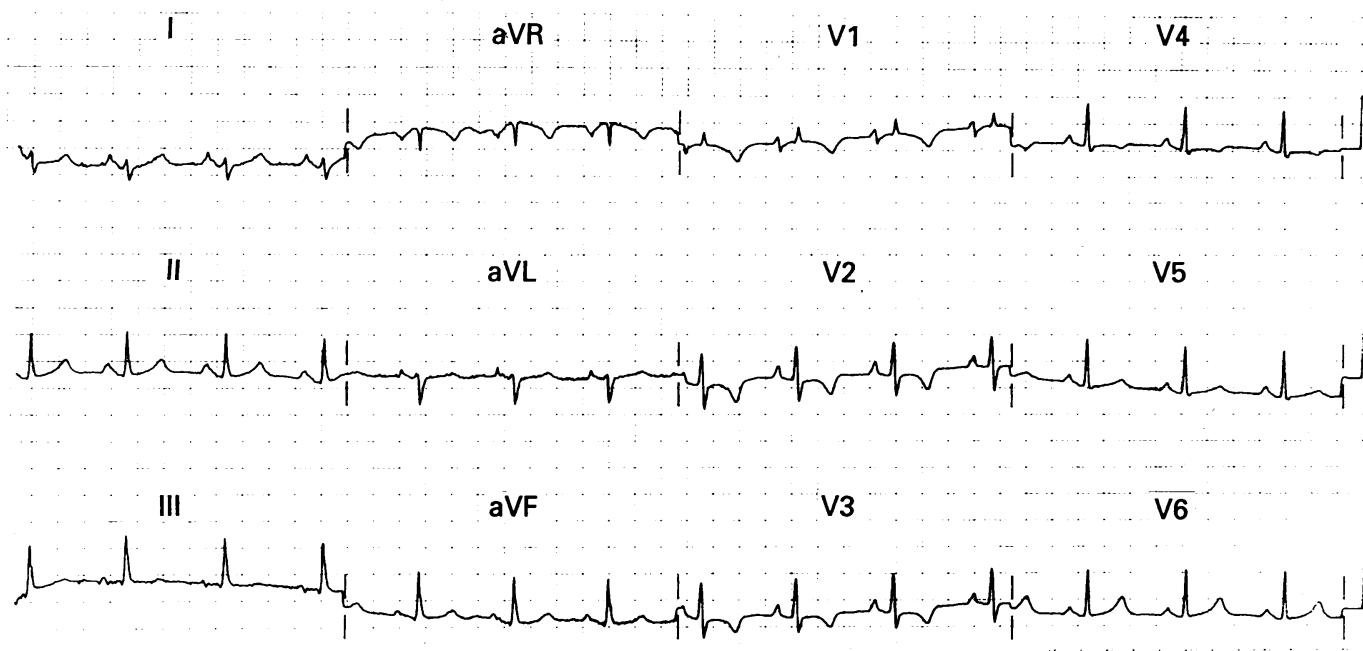

Rhythm strip: II

$25 \mathrm{~mm} / \mathrm{s} ; 1 \mathrm{~cm} / \mathrm{mV}$

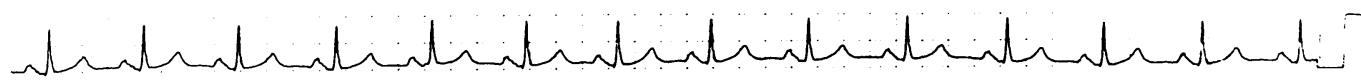

At the age of 36 she had her first cardiological referral. She was short $(1.54 \mathrm{~m}, 52 \mathrm{~kg})$ and had unusual facies with some characteristics of Noonan syndrome, including hypertelorism with a flat nasal bridge and cubitus valgus. She did not have a webbed or a short neck, low-set or abnormal ears, ptosis, downward slanting palpebral fissure, or epicanthal folds. She had clubbed digits with poor peripheral perfusion. Blood pressure was $100 / 70 \mathrm{~mm} \mathrm{Hg}$. Jugular venous pressure was $4 \mathrm{~cm}$ above the sternal angle with a dominant "a" wave. The left ventricular impulse was normal but the right ventricle was prominent. The second heart sound was widely split but mobile. There was no murmur.

The electrocardiogram was unchanged. The chest $x$ ray showed right heart prominence but normal pulmonary arteries and clear lung fields. Blood gases were $\mathrm{pH} 7 \cdot 44$, $\mathrm{PCO}_{2} 4.15 \mathrm{kPa}, \mathrm{Po}_{2} 8.04 \mathrm{kPa}$ and haemoglobin saturation was $92 \%$. Lung function tests (spirometry, lung volumes, flow-volume loops, and transfer factor) and thyroid function were normal.

The transthoracic echocardiogram showed

Table 1 Oxyhaemoglobin saturations

\begin{tabular}{lc}
\hline Site & $\%$ \\
\hline Inferior vena cava & 68 \\
Superior vena cava & 63 \\
High right atrium & 62 \\
Mid right atrium & 64 \\
Low right atrium & 66 \\
Right ventricular body & 61 \\
Right ventricular outflow & 62 \\
Main pulmonary artery & 64 \\
Right pulmonary artery & 66 \\
Left pulmonary artery & 64 \\
Left upper pulmonary vein & 97 \\
Left lower pulmonary vein & 98 \\
Left atrium & 92 \\
Left ventricle & 92 \\
Aorta & 93 \\
Aorta with balloon catheter & 96 \\
\hline `Inflated in left atrium and pulled back against the interatrial \\
septum.
\end{tabular}

a dilated right atrium and ventricle. The left heart and valves were normal. A right-to-left interatrial shunt was visible on contrast echocardiography without provocative manoeuvres and appeared large according to criteria we have used previously. ${ }^{34}$ A $19 \%$ shunt was found by superimposing a plot of five measurements of arterial $\mathrm{PO}_{2}$ against $\mathrm{FiO}_{2}$ of $0 \cdot 21,0 \cdot 4,0 \cdot 6,0 \cdot 8$, and $1 \cdot 0$ on iso-shunt lines. ${ }^{5}$

The main findings at cardiac catheterisation were a stepdown in haemoglobin saturation in the left atrium (table 1). When a balloon-tipped catheter was passed across the interatrial septum, the balloon was inflated and pulled back against the septum to occlude the patent foramen ovale arterial saturation reproducibly rose from $92-93 \%$ to greater than $96 \%$. Left heart and pulmonary artery pressures were normal but right heart filling pressures were raised with a dip and plateau waveform for right ventricular diastolic pressure. The mean right and left atrial pressures were similar but the waveforms differed with a higher "a" wave in the right atrium than the left (table 2). The right atrial

Table 2 Haemodynamic variables

\begin{tabular}{lll}
\hline Site & Wave & Pressure $(\mathrm{mm} \mathrm{Hg})$ \\
\hline Right atrium & $\mathrm{a}$ & 14 \\
& $\mathrm{x}$ & 6 \\
& $\mathrm{v}$ & 10 \\
& $\mathrm{y}$ & 9 \\
Rean & 10 \\
Pught ventricle & Phasic & $18 / 5-12$ (dip and plateau) \\
& Phasic & $18 / 7$ \\
Left atrium & Mean & 10 \\
& $\mathrm{a}$ & 12 \\
& $\mathrm{x}$ & 8 \\
& $\mathrm{v}$ & 12 \\
Left ventricle & y & 8 \\
Aorta & Phasic & $135 / 4-8$ \\
Cardiac output & Phasic & $135 / 86$ \\
Cardiac index & & 106 \\
& & $2.61 / \mathrm{min}$ \\
\end{tabular}




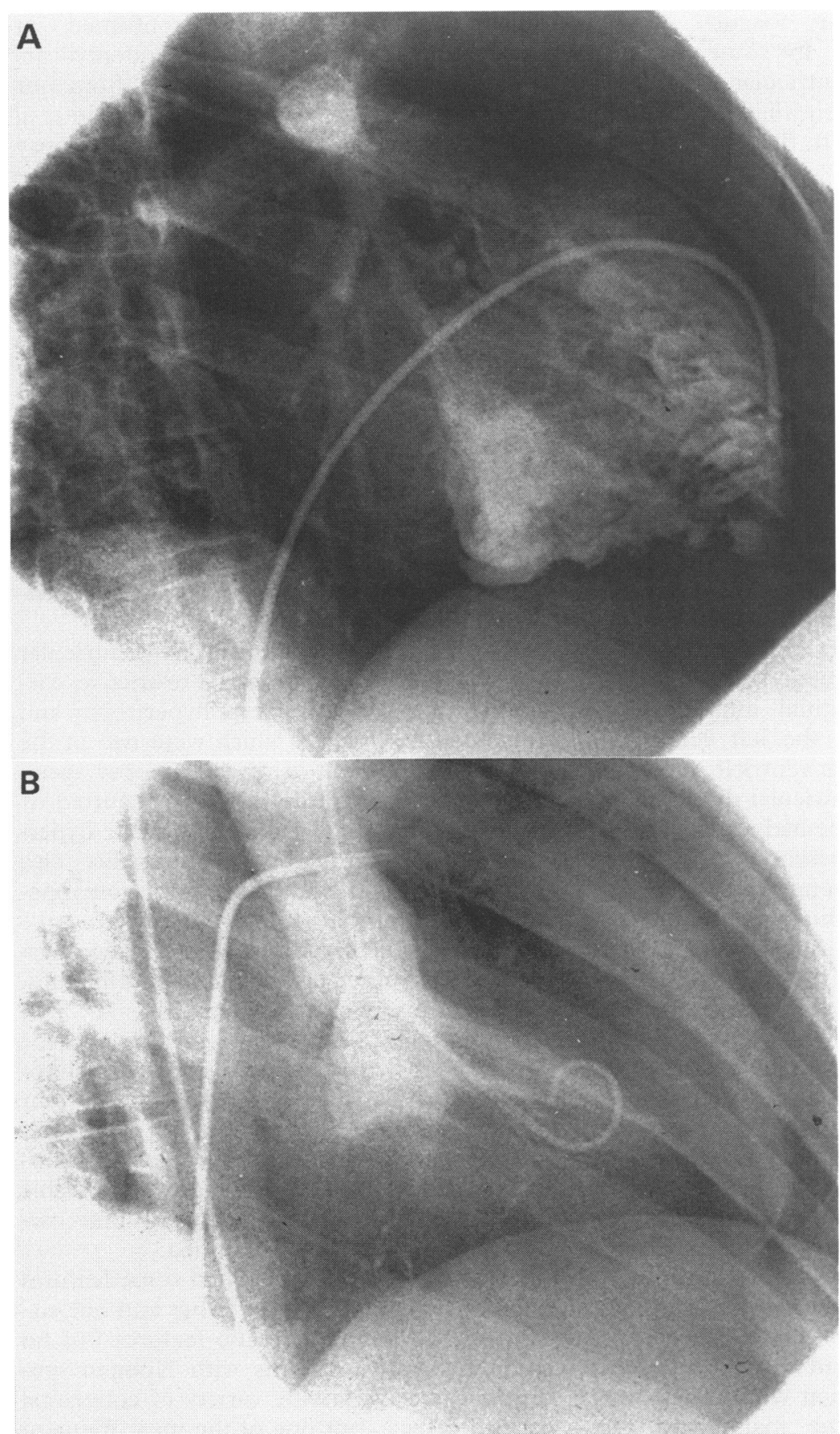

Figure 2 Systolic frames of right $(A)$ and left $(B)$ ventricular angiograms in the right anterior oblique projection.

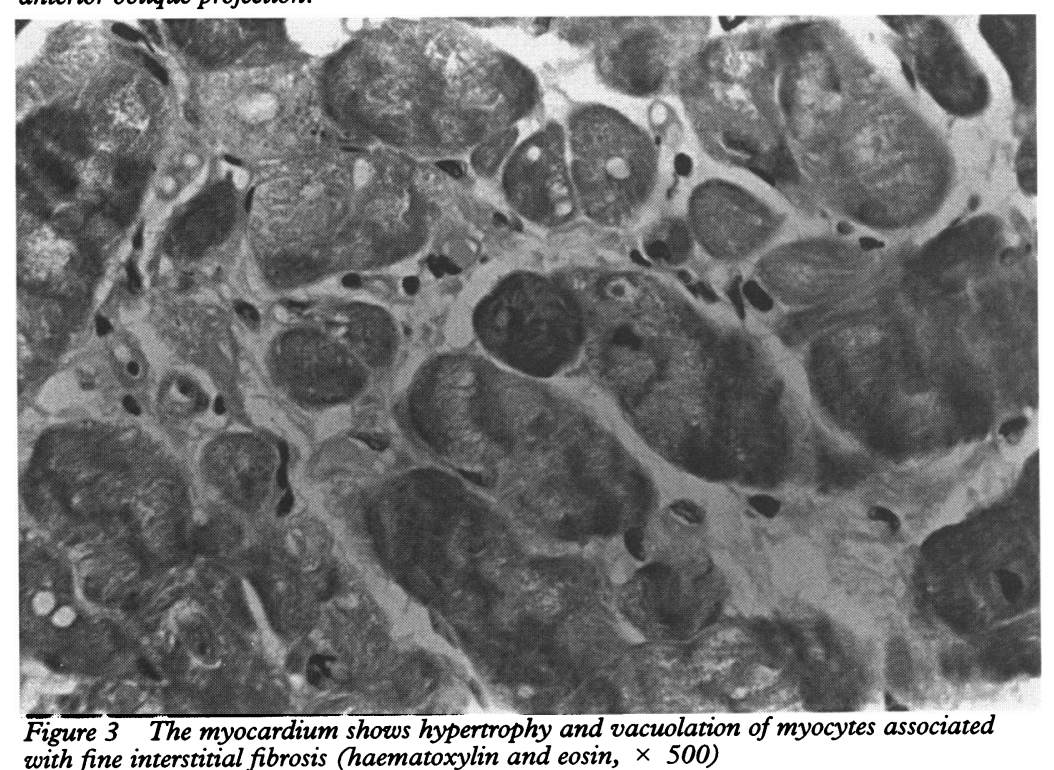

" $a$ " wave remained relatively higher than the left atrial " $a$ " wave when filling was varied slightly. The cardiac index was low.

Right atrial angiography showed a right-toleft shunt across a patent foramen ovale with the flap clearly seen with the atrial septum in profile. Left atrial angiography showed no left-to-right shunt. Right ventricular angiography showed a dilated, thin-walled, and hypokinetic ventricle (fig 2 ). There was mild tricuspid regurgitation. Handshots showed normal systemic and pulmonary venous drainage. Pulmonary arteriography and follow-through, left ventricular angiography (fig 2), and coronary arteriography were normal. The right coronary artery was dominant.

Two right ventricular endomyocardial biopsy specimens were taken. Histological examination showed fibre hypertrophy, vacuolation, and degeneration with fine interstitial fibrosis (fig 3). There was no infiltration with fat, inflammatory cells, or other material.

An open pericardial biopsy was performed to exclude constriction. The parietal and visceral pericardia were thin and smooth and the pericardial space was patent.

Because it was difficult to explain the patient's clubbing and degree of polycythaemia with only mild arterial desaturations (92-93\%) measured at cardiac catheterisation, greater degrees of desaturation were sought in other physiological situations by means of pulse oximetry. When upright her arterial saturations were $90-92 \%$. Though she was unable to exercise for more than one minute of the Bruce protocol because of fatigue and dyspnoea desaturation did not increase. During two overnight studies arterial saturation fell during sleep to $75-80 \%$, but there was no evidence of sleep apnoea.

Twenty four hour electrocardiograms did not show arrhythmia.

\section{FAMILY STUDY}

The father of the patient and one of her three sisters had similar facial appearances and short stature. Her father (age 74 years) had downward sloping palpebral fissures and epicanthal folds. He was treated for mild hypertension but cardiovascular findings were otherwise normal. His resting electrocardiogram showed voltage criteria for left ventricular hypertrophy but no other abnormality. His echocardiogram showed mild concentric left ventricular hypertrophy. Cardiovascular examination, electrocardiograms, and transthoracic echocardiograms were normal in the patient's mother (age 66 years) and her three sisters. Her brother declined investigation.

\section{Discussion}

In a review of 481 reported cases of right ventricular myodystrophy Gerlis and colleagues found that the description suggested Uhl's anomaly in 84 cases and arrhythmogenic right ventricular dysplasia in $397 . .^{1}$ The clinical diagnosis requires exclusion of coronary 
artery disease, pulmonary vascular disease, and valve abnormality. In some cases of arrhythmogenic right ventricular dysplasia a family history suggests mendelian inheritance ${ }^{16}$ and a gene associated with this condition has recently been identified.

Though the usual presenting features of right ventricular dysplasia are arrhythmias and sudden death, a patient with restrictive right sided haemodynamics has been described. $^{2}$ In that case, a 56 year old man presented with right heart failure. Asymptomatic, non-sustained ventricular tachycardia was present on 24 hour Holter monitoring and he died suddenly one year later. Endomyocardial biopsy specimens showed prominent interstitial and replacement fibrosis of the subendocardial myocardium, accompanied by myocyte hypertrophy and degeneration, without evidence of inflammation or infiltration. Electron microscopy showed large mitochondria with unusually arranged cristae. Only necropsy showed interstitial infiltration by adipose tissue involving the left ventricular apex and most of the right ventricle, typical of arrhythmogenic right ventricular dysplasia.

The patient we describe had right ventricular dysplasia that was present in early childhood and was probably congenital. There was no family history of cardiomyopathy or right ventricular dysplasia. Investigation of five first degree relatives showed no evidence of cardiomyopathy, but some family members had some characteristics of Noonan syndrome.

The haemodynamic findings were consistent with pure right ventricular restriction with no abnormality of left ventricular haemodynamics. There was no clinical or electrocardiographic evidence of arrhythmias. The patient's electrocardiogram showed repolarisation abnormalities, which are one of the proposed minor criteria for diagnosis of arrhythmogenic right ventricular dysplasia cardiomyopathy. ${ }^{8}$ She also had a major criterion-severe dilatation and reduction of right ventricular ejection fraction without left ventricular impairment. One major and one minor criteria would be insufficient for a diagnosis of right ventricular dysplasia according to the proposed classification. ${ }^{8}$ These requirements, however, may be too strict. Many patients with undoubted right ventricular dysplasia would not fulfil the requirement and many would achieve the diagnosis only after sudden death and necropsy. An excessive false negative rate in life reduces the value of the classification for patient counselling and for research, including genetic linkage analysis. Some patients with arrhythmogenic right ventricular dysplasia have significant left ventricular involvement. ${ }^{9}$ In others, symptoms are the result of heart failure rather than arrhythmias and death may result from heart failure not sudden death. ${ }^{9}$ Our patient did not have fibrofatty replacement of the myocardium on endomyocardial biopsy, which is another major criterion. ${ }^{8}$ This can be patchy, however, and can be missed with endomyocardial biopsy, but subsequently confirmed at necropsy. ${ }^{2}{ }^{8}$ Unfortunately the endomyocardial biopsy specimens were taken from our patient before the report by Blankenship et al was published. ${ }^{2}$ We did not send our biopsy specimens for electron microscopy, so we are unable to comment on mitochondrial appearance.

Pure right ventricular restriction is more common in other conditions, such as restrictive-obliterative endocardial disease (endomyocardial fibrosis and Loeffler's endocarditis) and localised pericardial constriction. These conditions and infiltrative diseases producing restriction were excluded by endomyocardial and pericardial biopsy. Primary restrictive cardiomyopathy affects both ventricles but in some individuals right sided symptoms predominate and haemodynamic features of restriction may be greater in the right ventricle than the left. ${ }^{10}$

Histological examination of left ventricular biopsy specimens in primary restrictive cardiomyopathy shows myocyte hypertrophy and interstitial fibrosis, ${ }^{11-13}$ which were two of the features of the right ventricular biopsy specimens in this patient and the one reported by Blankenship and colleagues. ${ }^{2}$ Myocyte hypertrophy is a non-specific abnormality also found in patients with dilated cardiomyopathy and hypertrophic cardiomyopathy.

Hypertrophic cardiomyopathy is also characterised by other histological abnormalities, notably myocyte disarray, and a well described clinical phenotype. The phenotype varies greatly as a result of genetic heterogeneity. So far several mutations and four genetic loci have been discovered that result in the hypertrophic cardiomyopathy phenotype $^{14}$ but the genetic mutations responsible for about half the cases of hypertrophic cardiomyopathy remain unidentified.

The patient we describe had some features of Noonan syndrome. Her father and one sister also had similar somatic features but no cardiomyopathy. Patients with Noonan syndrome can have a wide variety of congenital cardiac defects, but one of the most frequent abnormalities is a cardiomyopathy with some features in common with hypertrophic cardiomyopathy. Noonan cardiomyopathy is characterised histologically by myocyte hypertrophy and disarray and the haemodynamic findings can be either obstructive or nonobstructive. ${ }^{15} 16$ There has been no linkage, so far, with any of the gene mutations known to be associated with hypertrophic cardiomyopathy. The patient we describe had a form of restrictive cardiomyopathy affecting the right ventricle only. Primary restrictive cardiomyopathy affecting both left and right ventricles has recently been described in members of a family with Noonan syndrome, but histological examination of the heart was not done. ${ }^{17}$ We are aware of another case of primary restrictive cardiomyopathy associated with Noonan syndrome in which cardiac biopsy specimens showed myocyte hypertrophy without disarray, and in which there was no macroscopic hypertrophy or other features of 
hypertrophic cardiomyopathy (unpublished observations).

Whatever the cause of the cardiomyopathy in this patient, the unusual presenting features were as much a result of a coincident patent foramen ovale, which allowed right-toleft shunting. This occurred despite similar mean right and left atrial pressures, because the flap-valve effect of the defect allowed oneway passage of blood at those times in the cardiac cycle when the right atrial pressure was relatively high.

During the day the patient had only mild degrees of arterial desaturation, which were insufficient to explain her polycythaemia or clubbing. Posture and exercise can affect the amount of shunting and hence the degree of arterial desaturation in subjects with a patent foramen ovale. ${ }^{41819}$ In this patient postural changes, variations in filling pressures, and the small amount of exercise of which she was capable had only small effects on arterial saturation. There was a marked reduction in arterial saturation during sleep, which was not the result of supine posture nor of apnoea. It is possible that the mild hypoventilation, which is normal during sleep, rather than apnoea, was sufficient to reduce $\mathrm{Po}_{2}$ enough to cause descent along the steep part of the oxyhaemoglobin dissociation curve, to levels of desaturation sufficient to result in clubbing and polycythaemia.

1 Gerlis LM, Schmidt-Ott SC, Ho SY, Anderson RH. Dysplastic conditions of the right ventricular myocardium: Uhl's anomaly $v$ arrhythmogenic right myocardium: Uhl's anomaly $v$ arrhythmogenic

2 Blankenship DC, Hug G, Balko G, van der Bel-Kann J, Coith RL, Engel PJ. Hemodynamic and myocyte mitochondrial ultrastructural abnormalities in arrhythmogenic right ventricular dysplasia. Am Heart $\mathcal{F} 1993$

3 Webster MWI, Chancellor AM, Smith JH, Swift DL, Sharpe DN, Bass NM, et al. Patent foramen ovale in young stroke patients. Lancet 1988;ii:11-2.

4 Wilmshurst PT, Byrne JC, Webb-Peploe MM. Relation between interatrial shunts and decompression sickness in divers. Lancet 1989;ii:1302-5.

5 Benatar SR, Hewlett AM, Nunn JF. The use of iso-shunt lines for control of oxygen therapy. $\mathrm{Br} \mathcal{F}$ Anaesth 1973;45:711-8.

6 Miani D, Pinamonti B, Bussani R, Silvestri F, Sinagra G, Camerini F. Right ventricular dysplasia: a clinical and pathological study of two families with left ventricular involvement. Br Heart f 1993;69:151-7.

7 Rampazzo A, Nava A, Danieli GA, Buja G, Daliento L, Fasoli G, et al. The gene for arrhythmogenic right ventricular cardiomyopathy maps to chromosome 14q23-24. Human Molecular Genetics 1994;3:959-62.

8 McKenna WJ, Thiene G, Nava A, Fontaliran F, Blomstrom-Lundqvist C, Fontain G, et al on behalf of the Task Force of the Working Group Myocardial and Pericardial Disease of the European Society of Cardiology and of the Scientific Council on Cardiomyopathies of the International Society and Federation of Cardiology, supported by the Schoepfer Association. Diagnosis of arhythmogenic right ventricular dys

9 Pinamonti B, Sinagra G, Salvi A, Di Lenarda A, Morgera $\mathrm{T}$, Silvestri $\mathrm{F}$, et al. Left ventricular involvement in right ventricular dysplasia. Am Heart f 1992;123:711-24.

10 Hirota Y, Shimizu G, Kita Y, Nakayama Y, Suwa M, Kawamura $\mathrm{K}$, et al. Spectrum of restrictive cardiomyopathy: report of the national survey in Japan. Am Heart f 1990;120:188-94.

11 Katritsis D, Wilmshurst PT, Wendon JA, Davies MJ, Webb-Peploe MM. Primary restrictive cardiomyopathy: clinical and pathologic characteristics. $\mathcal{F} \mathrm{Am}$ Coll Cardiol 1991;18:1230-5.

12 Fitzpatrick AP, Shapiro LM, Rickards AF, Poole-Wilson PA. Familial restrictive cardiomyopathy with atrioventricular block and skeletal myopathy. $\mathrm{Br}$ Heart $\mathcal{f}$ 1990;63:114-8.

13 Aroney C, Bett N, Radford D. Familial restrictive cardiomyopathy. Aust NZF Med 1988;18:877-8.

14 Watkins HC, Thierfelder LH, MacRae CA, Yeon H, McKenna WJ, Seidman JG, et al. Analysis of genetic ocus heterogeneity in hypertrophic cardiomyopathy [abstr]. Br Heart f 1994;71(suppl):P49

15 Phornphutkul C, Rosenthal A, Nadas AS. Cardiomyopathy in Noonan's syndrome. Report of 3 cases. Br Heart $\mathcal{F}$ 1973;35:99-102.

16 Mendez HMM, Opitz JM. Noonan syndrome: a review. Am $\mathcal{F}$ Med Genet 1985;21:493-506.

17 Cooke RA, Chambers JB, Curry PVL. Noonan's cardiomyopathy: a non-hypertrophic variant. $B r$ Heart $f$ 1994;71:561-5.

18 Seward JB, Hayes DL, Smith HC, Williams, DE, Rosenow EC, Redder GS, et al. Platypnea-orthodeoxia: clinical profile, diagnostic workup, management, and report of seven cases. Mayo Clin Proc 1984;59:221-31.

19 Wilmshurst PT, Treacher DF, Crowther A, Smith SE. Wilmshurst PT, Treacher DF, Crowther A, Smith SE.
Effects of a patent foramen ovale on arterial saturation Effects of a patent foramen ovale on arterial saturation
during exercise and on cardiovascular responses to deep breathing. Valsalva manoeuvre, and passive tilt: relation breathing. Valsalva manoeuvre, and passive tilt: relation
to history of decompression illness in divers. Br Heart $\mathcal{f}$ 1994;71:229-31. 